\title{
Polifenóis no vinho: resveratrol e seus benefícios
}

\section{Polyphenols in wine: resveratrol and its benefits}

Recebido em: 22/06/2016

Aceito em: $\quad 09 / 11 / 2016$
Pâmela Padovani MARTINS ${ }^{1}$, Maria Aparecida NICOLETTI ${ }^{2}$

${ }^{1}$ Universidade Guarulhos - Ser Educacional. Pca. Tereza Cristina, $n^{\circ} 88$, Centro, Guarulhos, CEP 07023-070. SP, Brasil. ${ }^{2}$ Departamento de Farmácia, Faculdade de Ciências Farmacêuticas, Universidade de São Paulo. Avenida Professor Lineu Prestes, 580 - Bloco 15, CEP 05508-900. São Paulo,SP, Brasil.E-mail: ppmpam@gmail.com

\section{ABSTRACT}

The research was directed to the peculiar characteristics of the wine, aiming to clarify the benefits, considering some assets present its composition. The objective was to elucidate what, how and why the substances in wine (especially resveratrol) benefit the human body, by a retrospective descriptive study using as sources of technical and scientific information: Electronic database of the Scientific Electronic Library Online (SciELO), National Institutes of Health (PubMed and MEDLINE), Regional Library of Medicine (BIREME), and sources secondary in the period 1994-2015, which was to search focus studies and research conducted on animals and human models, and scientific evidence that addressed mainly the effects of resveratrol. The research showed resveratrol's ability to prevent atherosclerosis, inflammatory and allergic diseases, heart problems, among other ailments. Among the substances found in wine, resveratrol stands out for its therapeutically beneficial properties.

Keywords: Polyphenols, Tannin, Wine.

\section{RESUMO}

A pesquisa foi direcionada para abordar as características peculiares do vinho, visando esclarecer os seus benefícios, considerando alguns ativos presentes sua composição. O objetivo foi elucidar o quê, como e o porquê as substâncias contidas no vinho (em especial, o resveratrol) beneficiam o organismo humano, por meio de um estudo descritivo e retrospectivo utilizando-se como fontes de informação técnico-científica: bases eletrônicas de dados da Scientific Electronic Library Online (SciELO), National Institutes of Health (PubMed e MedLine), Biblioteca Regional de Medicina (BIREME), além de fontes secundárias, no período de 1994 a 2015, que teve como foco de busca os estudos com evidência científica realizados com modelos animais e, também, em humanos, principalmente, quanto aos efeitos do resveratrol. A pesquisa evidenciou a capacidade do resveratrol em evitar a arteriosclerose, as doenças inflamatórias e alérgicas, os problemas cardíacos, entre outros agravos à saúde. Dentre as substâncias encontradas no vinho, o resveratrol destaca-se por suas propriedades terapêuticas benéficas.

Palavras Chaves: Polifenóis, Taninos, Vinho

\section{INTRODUÇÃO}

A grande procura da humanidade por meios que favoreçam uma vida saudável tem impulsionado as pesquisas por novas substâncias capazes de satisfazer tais necessidades. Entre estas substâncias encontram-se os polifenóis, destacando-se as pesquisas do resveratrol que está presente em diversas plantas, em especial na uva e seus derivados (1).
A produção de vinho brasileiro tornou-se uma atividade comercial a partir do século XX, sendo que até a década de 60, a viticultura limitou-se às regiões Sul e Sudeste. As características sensoriais atraem o consumo do vinho, porém, são os compostos fenólicos, os dignos de mérito quanto aos benefícios à saúde $(2,3)$.

O vinho é uma bebida alcoólica resultante da transformação biológica da uva que contém substâncias fenólicas, como os flavonoides, os estilbenos (resve- 
ratrol), os ácidos fenólicos e uma grande variedade de taninos $(3,4)$.

Antigamente, as propriedades benéficas ao sistema cardiovascular decorrentes da ingestão do vinho eram atribuídas à presença do álcool; entretanto, o vinho vem sendo estudado quanto à sua constituição, para a elucidação dos compostos presentes. Entre os polifenóis encontrados no vinho, destaca-se o resveratrol (3,5,4'-triidroxiestilbeno), encontrado na casca da uva, especialmente em células epidérmicas e sementes; entretanto, apresenta baixa concentração na polpa e, está presente, principalmente, nas uvas tintas. Possui ação na prevenção de aterosclerose, que é decorrente da diminuição da agregação plaquetária e, apresenta atividade biológica como cardioprotetora, neuroprotetora, antienvelhecimento e anticancerígena. Quanto a este último agravo à saúde, o resveratrol promove a inibição da cascada do ácido araquidônico, sendo esta rota metabólica que poderá induzir a gênese de tumores $(3,5,6,7)$.

Alguns estudos realizados indicaram que os polifenóis modulam a atividade de diversos fatores de transcrição, o que provoca a diminuição de citocinas inflamatórias e de moléculas de adesão, e aumento da expressão de enzimas antioxidantes levando, entretanto, em consideração, que tais mecanismos moleculares de ação não estejam totalmente esclarecidos. Em estudo realizado ressaltando maiores detalhes, a administração sistêmica de resveratrol bloqueou o aumento da agregação de plaquetas e, sua atividade anti-inflamatória foi explicada pela inibição da transcrição e atividade da ciclooxigenase (COX-1 e COX-2) inibindo, também, a síntese de tromboxinas e, portanto, atuando como anticoagulante $(5,7,8)$.

O Brasil cada vez mais tem se mostrado como produtor de boas safras de vinhos, e o mercado da vinicultura, nacional ou internacional, cresceu intensamente nos últimos anos. Portanto, por ser bebida que atualmente tem sido difundida decorrente de seu paladar agradável, além de suas propriedades benéficas à saúde, faz-se necessário a realização de levantamento que evidencie, cientificamente, a ação farmacológica decor- rente de compostos presentes em sua composição.

O objetivo desta revisão é identificar publicações científicas que abordem os benefícios decorrentes do resveratrol no vinho, que vem a ser um de seus principais componentes químicos, esclarecendo sua origem, composição e quantidades recomendadas.

\section{MATERIAIS E MÉTODOS}

Foi realizado um estudo descritivo e retrospectivo de revisão bibliográfica com a utilização de bases de dados científicas acessadas eletronicamente: Biblioteca Regional de Medicina (BIREME), Scientific Electronic Library Online (SciELO) e Literatura Internacional em Ciências da Saúde (MEDLINE via PubMed). Fontes terciárias, também, foram empregadas como complementação. O intervalo temporal utilizado foi de 1994 a 2015, exceto pela contextualização histórica. Foram utilizados os descritores em português, inglês e espanhol, respectivamente: polifenois, resveratrol e vinho; polyphenols, resveratrol e wine; polifenoles, resveratrol e vino. O critério de inclusão adotado baseou-se no período de anos proposto para a pesquisa e o foco do estudo estar diretamente relacionado aos componentes do vinho e sua ação farmacológica.

\section{RESULTADOS E DISCUSSÃO}

O vinho é o produto obtido pela fermentação alcoólica total ou parcial da uva fresca do mosto da uva, contendo geralmente de 10 a $15 \%$ de álcool (9). Sua história é de longa data e os principais acontecimentos relacionados estão representados na Figura 1.

A origem do vinho é anterior ao surgimento da escrita. Tal afirmação se deve pelo achado de sementes, em cavernas no período paleolítico. Existindo a uva, certamente, haveria também o vinho, obtido pela fermentação por meio da atividade de leveduras silvestres presentes em suas cascas, isto podendo acontecer em reação espontânea em frutos esmagados e guardados em recipientes (10). 


\section{Unizanana}

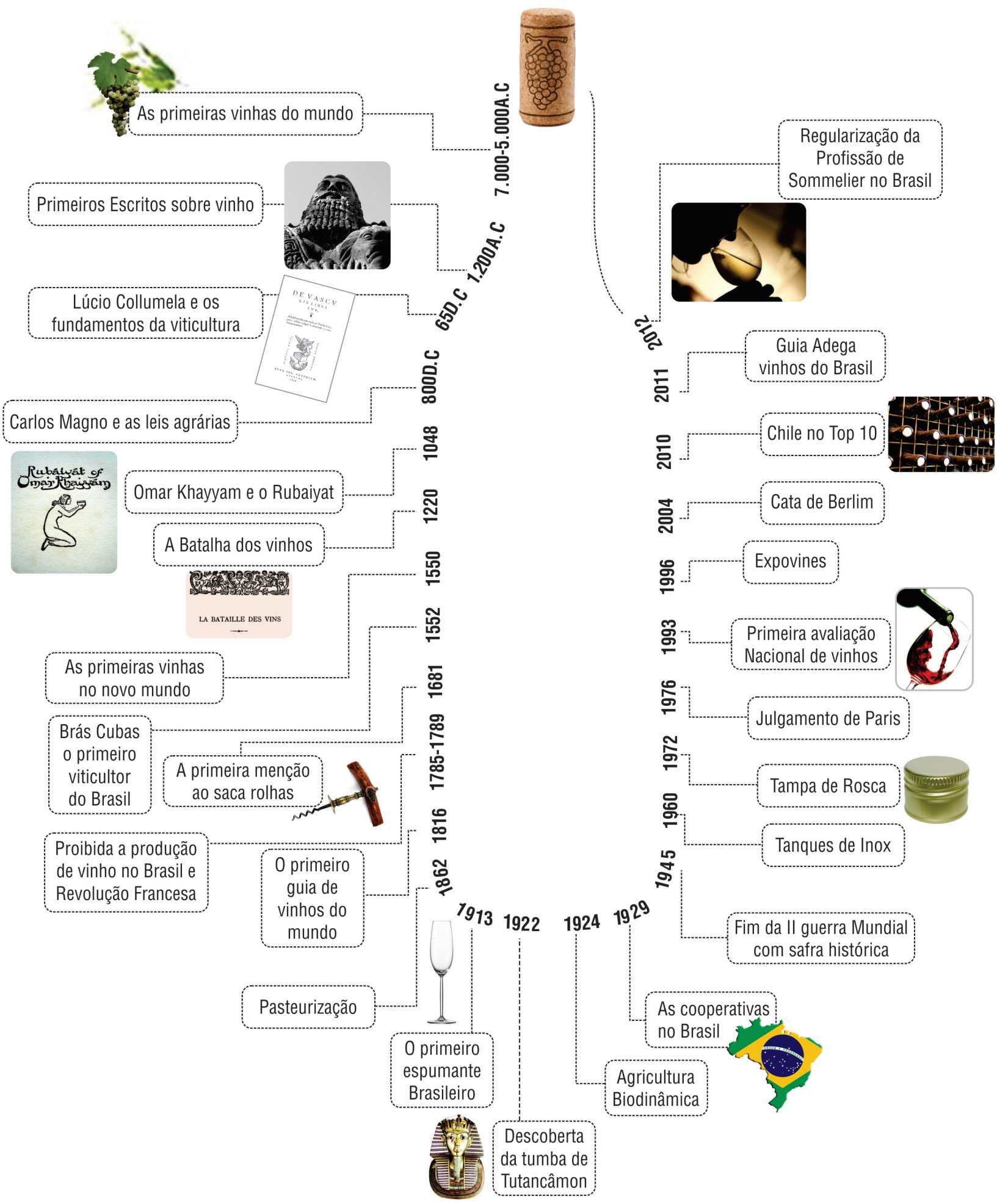

Figura 1: Síntese dos principais momentos históricos relacionados ao vinho 
Cientistas acreditam que os primeiros indícios de viticultura foram encontrados na Geórgia, na região do Cáucaso e no sul do Mar Negro, na idade da Pedra. Quando isto ocorreu é difícil precisar, mas pesquisas afirmam que a videira começou a ser cultivada por volta de 6000 a.C. Acredita-se que os vinhos tenham surgido também nesse período, apesar de as primeiras prensas e outros equipamentos vitivinícolas que foram encontrados na Armênia datam de 4.000 a.C. $(10,11)$.

Mais tarde, descobertas indicaram a região da Mesopotâmia como local da presença de bebida, em torno de 3500 a.C., com participação assíria e fenícia nas terras de Canaã. Também, é citado historicamente o Egito participando destas descobertas com achados arqueológicos de 3000 a.C. Desta maneira, começou a disseminação deste conhecimento, por parte dos fenícios, por meio do mediterrâneo chegando aos Gregos em 2000 a.C (10).

Em 1800 a.C. o primeiro livro da Bíblia, o Gênesis, conta que Noé se tornou lavrador e plantou um vinhedo. O Talmude, livro sagrado dos judeus, também fala sobre vinho, símbolo tradicional da felicidade e de ocasiões festivas, fazendo parte de uma reza (Kidúsh - Satisfação) reconhecendo que Deus é o criador e o Shabat (dia de guarda, sábado) é um dia santo $(11,12)$.

Para os gregos, o vinho transformou-se em dádiva dos deuses, adotando como patrono Dionísio, filho de Zeus. Com a expansão helênica, o cultivo da videira desenvolveu-se a partir de 1000 a.C., indo à Sicília e África do Norte. Na Itália, foram implantadas importantes colônias como a atual Nápoles e Magma Grécia, envolvendo o extremo sul compartilhado pela Sicília, Calábria e Puglia, onde pontificaram as cidades de Siracusa e Taranto. A este conjunto foi dado o nome de Enótria Tellus (Terra do Vinho). Em 750 a.C., Homero citou em suas narrativas épicas, tanto a história da Guerra de Troia, na Ilíada, quanto as aventuras de Ulisses, na Odisseia, relatos de consumo e produção de vinho na época. Nos séculos que se seguem, o conhecimento do vinho chega à Península Ibérica e França, por volta de 600 a.C., onde acaba fundando a atual cidade de Marselha $(10,11)$.

Em 65 d.C., o espanhol Lúcio Columella escreveu o mais completo manual de agricultura até então, denominado De Re Rustica. Uma grande ênfase à viticultura está em seu livro, e muitas das técnicas descritas ainda são utilizadas atualmente. Carlos Magno em 850 d.C., entre suas realizações, promulgou leis agrárias, especialmente as ligadas ao vinho, com normas rígidas para a produção (11).

No Brasil, nas duas últimas décadas, o consumo de vinho tem apresentado crescimento acentuado. A maior parte deste crescimento no consumo baseia-se em vinhos provenientes de outros países. Segundo dados da Secretaria de Comércio Internacional (Secex) do Ministério do Desenvolvimento, Indústria e Comércio (MDIC), para o período entre 1995 e 2014, mostram que a importação brasileira de vinhos estrangeiros apresentou taxa de crescimento de 11,2\% ao ano (13).

A quantidade de substâncias que compõe o vinho é diversa (800 a 1.000), e estão listadas, a seguir, algumas que apresentam relevância $(10,11,14,15,16)$ :

- Água: representa $80 \%$ de seu volume.

- Álcool: pode variar de $6 \%$ a mais de $20 \%$. O álcool etílico é produzido por meio da fermentação dos açúcares da uva (por leveduras).

- Glicerina ou glicerol: sua quantidade no vinho varia entre os 5 e $12 \mathrm{~g} / \mathrm{L}$. Trata-se de álcool trivalente e grande responsável pela maciez do vinho, diminuindo a acidez e adstringência.

- Ácidos Orgânicos: uns são provenientes da uva - como os ácidos tartárico, málico e cítrico - e outros resultantes da fermentação, como o succínico, o láctico e o acético. Este último representa a acidez volátil, enquanto os cinco primeiros constituem a acidez fixa; e juntos formam a acidez total do vinho. Além desses, existem outros ácidos em quantidades diminutas. Os ácidos mais importantes são o tartárico e o málico. Existem castas de uvas mais ricas em ácidos do que outras.

- Açúcar residual (AR): sua quantidade varia conforme o tipo de vinho ou mercado a que se destina. $\mathrm{O}$ açúcar residual é aquele que não foi transformado em álcool e é representado pela frutose e glicose. Para cada grau alcoólico são necessários 17 gramas de açúcar por litro.

- Polifenois: são substâncias químicas de composições variadas, sendo um de seus principais integrantes o tanino, em que uma de suas substâncias ativas é o resveratrol. Os polifenois apresentam uma estrutura química comum, derivada do benzeno, ligada a um grupo hidrofílico. Com base em sua estrutura e na maneira pela qual os anéis polifenólicos 


\section{Anganama}

ligam-se uns aos outros, eles são classificados em quatro famílias: flavonoides (flavonas, flavanonas, catequinas e antocianinas), ácidos fenólicos, lignanas e estilbenos (à qual pertence o resveratrol).

Além dos componentes citados anteriormente, também, fazem parte da composição do vinho: aldeídos/ ésteres/cetonas (os aldeídos são formados pela oxidação dos álcoois e os ésteres pela combinação de ácidos e álcoois, ambos representando importante papel na formação do aroma do vinho), sais minerais (sulfatos, cloretos, nitratos, cobre, flúor, etc., que são considerados importantes catalisadores nos processos bioquímicos), vitaminas $\left(\mathrm{B}_{1}, \mathrm{~B}_{2}, \mathrm{~B}_{6}\right.$ e $\left.\mathrm{B}_{12}\right)$ e aminoácidos $(17,18)$.

A recomendação médica é de $30 \mathrm{~g}$ de álcool por dia para os homens (cerca de $330 \mathrm{~mL}$ ) e $15 \mathrm{~g}$ para as mulheres $(165 \mathrm{~mL})$ o que equivale, para os homens, quase meia garrafa de vinho por dia, e para as mulheres a metade, pois são menos tolerantes ao álcool e têm menor proporção de água no organismo (19). De acordo com diversos especialistas, o consumo de uma ou duas taças de vinho tinto por dia, havendo uma boa absorção dos princípios ativos, é dose adequada para proteção do organismo por meio de diversos mecanismos fisiológicos $(4,20)$.

Alguns estudos indicam que o suco de uva teria efeitos quase iguais aos do vinho, tornando-se uma alternativa para quem não pode, ou não quer, tomar álcool (21). Assim, o suco de uva é uma fonte alternativa de resveratrol para os abstêmios, pois, conforme estudo realizado nos sucos de uva elaborados no Brasil, foi identificada a concentração de trans-resveratrol de 0,19 a $0,90 \mathrm{mg} / \mathrm{L}$ de suco de uva (1).

Compostos fenólicos. Compostos fenólicos fazem parte de uma classe de compostos que inclui uma diversidade de estruturas, simples ou complexas, que possuem no mínimo um anel aromático no qual, ao menos, um hidrogênio é substituído por um grupamento hidroxila. Têm sido amplamente estudados devido à sua influência na qualidade dos alimentos, englobando uma gama enorme de substâncias, entre elas, os ácidos fenólicos. Os polifenois também fazem parte do metabolismo animal, especificamente, nos microrganismos, e estão distribuídos amplamente no reino vegetal $(22,23)$.

Dentre os compostos bioativos nos vegetais, os polifenóis estão no maior grupo, dividindo-se em classes de acordo com a estrutura química de cada substância possuindo, em geral, características ácidas. Esses compostos são instáveis, ou seja, os fenóis são facilmente oxidados, principalmente, em meio básico $(22,24)$. Podem ser classificados segundo o tipo do esqueleto principal, conforme exemplificado no Quadro 1.

Quadro 1. Exemplos de alguns compostos fenólicos em relação à classificação com esqueleto básico. $C_{6}$ corresponde ao anel benzênico à cadeia substituinte com $X$ átomos de carbono $(10,22)$

\begin{tabular}{|c|c|}
\hline Esqueleto Básico & Classe de Compostos fenólicos \\
\hline$C_{6}$ & Fenóis simples, benzoquinonas \\
\hline$C_{6}-C_{1}$ & Ácidos fenólicos \\
\hline$C_{6}-C_{2}$ & Acetofenonas e ácidos fenilacéticos \\
\hline$C_{6}-C_{3}$ & Fenilpropanóides: ácido cinâmicos e compostos análogos, fenilpropenos, cumarinas, \\
isocumarinas e cromonas
\end{tabular}


Outro tipo de classificação relaciona a ocorrência destes compostos no reino vegetal: amplamente distribuídos (derivados de ácidos benzoicos e de ácidos cinâmicos, cumarinas, flavonoides e derivados de polimerização - taninos, ligninas), e compostos fenólicos de distribuição restrita. Tratando-se do vinho, os polifenois dividem-se em dois grupos: a- Flavonoides: catequinas, epicatequinas, flavonois (casca: miricetina, quercitina), antocianidois (casca); b- Não Flavonoides: ácido benzoico, ácido hidrociânico, estilbeno (resveratrol), ácido cafeico ou caftárico, ácido cutárico, ácido fertárico e ácido sinápico. Na uva, componente também de importância encontrado na parte interna de sua casca é o ácido tânico, que faz parte do grupo dos taninos responsáveis pela conservação, longevidade e complexidade do vinho (22).

Estes compostos conferem adstringência e sabor, além de atuar como conservantes, sendo os compostos fenólicos dignos de mérito em relação aos benefícios proporcionados à saúde. Alguns estudos realizados evidenciam correlação positiva entre a atividade antioxidante e o teor de compostos fenólicos totais $(10,24,25)$. Maiores teores de compostos fenólicos foram encontrados nos extratos etanólicos, demonstrando que etanol foi mais eficiente na extração dessa classe de substâncias químicas, o que explica a presença destes compostos no vinho, considerando que o álcool está presente em sua composição e, desta maneira, permite melhor extração destes compostos $(3,25)$.

São produtos de rota biossintética mista. São formados por meio de duas rotas biogenéticas: pela rota acetato-malonato, originando compostos com grupos hidroxilas, e pela via do ácido chiquímico, a partir de carboidratos, formando compostos com grupos hidroxilas em posição orto, que se formam a partir do ácido cinâmico. É importante ressaltar que os vegetais apresentam rotas biogenéticas alternativas, ou seja, capacidade de produzir um mesmo composto a partir de diferentes intermediários (22).

Apresentam-se em dois tipos: naturais ou sintéticos, e quando presentes em vegetais podem estar em formas livres ou complexadas a açúcares e a proteínas. A maior parte destes compostos não é encontrada em seu estado livre; mas sob a forma de ésteres e heterosídeos, portanto, são solúveis em solventes orgânicos polares e água. São compostos aromáticos e facilmente oxidados (por enzimas vegetais específicas, por influência de metais, luz, calor ou meio alcalino, o que ocasiona o escurecimento de suas soluções ou dos compostos isolados) $(22,26)$. Contribuem para o sabor, o odor e a coloração de diversos vegetais, sendo utilizados também como corantes e flavorizantes de alimentos e bebidas. A indústria alimentícia encontra nos compostos fenólicos (particularmente, nas antocianinas) um importante substituinte aos corantes artificiais. Ainda podem ser utilizados como conservantes e na prevenção de doenças associadas aos radicais livres (27). A quantidade e a qualidade dos polifenóis de uva dependem, principalmente, da variedade de videiras, clima, terreno e práticas colheita $(5,10,28,29)$.

Resveratrol. O resveratrol, substância ativa, é uma fitoalexina polifenólica encontrada abundantemente nas uvas e no vinho tinto. É sintetizado naturalmente na planta sob duas formas isôméricas: trans-resveratrol e cis-resveratrol, sendo a forma trans a mais estável.

O trans-reveratrol pode ser encontrado em várias plantas, inclusive nos vinhos tintos e tem sido alvo de estudos e sendo apontado como responsável por diversos benefícios à saúde humana. Os mecanismos moleculares de ação dos polifenóis não são totalmente esclarecidos. Nos estudos farmacocinéticos em animais e humanos, que são limitados, o resveratrol é absorvido no trato gastrintestinal após sua ingestão, porém, a farmacocinética não é integralmente conhecida $(8,30)$.

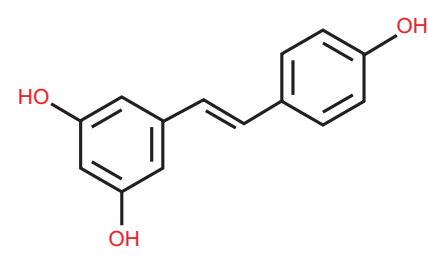

trans-resveratrol

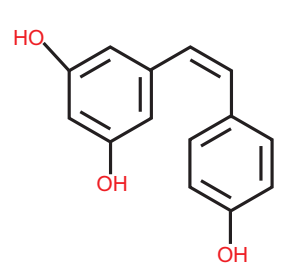

cis-resveratrol
Com o consumo contínuo e moderado de vinho tinto, as propriedades estrogênicas do resveratrol ocasionam importante efeito cardiovascular. De acordo com algumas pesquisas, é aconselhável adicionar o vinho tinto na dieta, considerando as propriedades anticarcinogênica e antiesclerótica $(21,26,31)$.

O resveratrol produz maior manifestação de alguns genes reguladores de novas drogas estrogênicas mais seletivas, sendo estes usados em tratamento de câncer de mama (tamoxifeno) e osteoporose pós-menopáusica (raloxifeno) (32). Além disso, possui atividade biológica como cardioprotetor, neuroprotetor, antienvelhecimento e anticancerígeno. Nos lipopolissacarídeos, o efeito é acompanhado por uma elevação de óxido nítrico em nível plasmático e nos órgãos, o que não foi observado na presença de resveratrol $(5,31,32)$.

Conhecido há muito tempo na terapêutica medicinal oriental vem sendo utilizado pelos chineses e japo- 


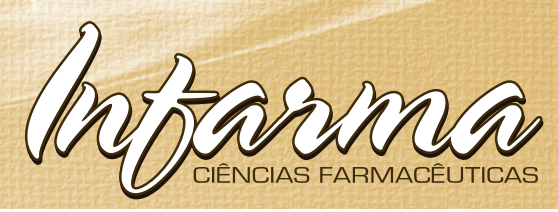

neses para tratamento de arteriosclerose, de doenças inflamatórias e alérgicas. Suas características polifenólicas permitem explicar suas atividades antioxidante e redutora de triglicerídeos. Apresenta a capacidade de modular o metabolismo dos lipídeos, e para inibir a oxidação de lipoproteínas de baixa densidade e a agregação de plaquetas $(32,33,34)$.

Alguns estudos realizados indicaram que os polifenois modulam a atividade de diversos fatores de transcrição, o que provoca a diminuição de citocinas inflamatórias e de moléculas de adesão, e aumento da expressão de enzimas antioxidantes, levando em consideração, que tais mecanismos moleculares de ação não estejam totalmente esclarecidos. Em estudo realizado ressaltando maiores detalhes, a administração sistêmica de resveratrol bloqueia o aumento da agregação de plaquetas, entre outros benefícios. Além disso, como fitoestrogênico, o resveratrol pode fornecer proteção cardiovascular, além de propriedades anti-inflamatórias e anticancerígenas $(5,8)$.

O resveratrol é capaz de modular a função da célula vascular, inibir a oxidação de LDL (Low Density Lipoproteins), suprimir a agregação de plaquetas e reduzir o dano do miocárdio durante a isquemia por reperfusão $(4,34,35)$.

Pivetta (2005), em texto que considerou os benefícios do vinho, citou o geneticista Gilson Cunha, que em pesquisa realizada utilizando resveratrol observou aumento em 30\% da longevidade da Drosophila melanogaster. Estudos com invertebrados, mamíferos e em cultura de tecidos sugerem que o resveratrol poderia, até certo ponto, imitar alguns efeitos benéficos de uma dieta com restrição de calorias, um procedimento que induz ao prolongamento da vida. Ainda o pesquisador menciona que família de genes denominada sirtuínas estaria ligada pelo consumo cuidadoso de derivados da uva, embora os mecanismos de ação do resveratrol não tenham sido completamente definidos, existe evidência de que alguns dos efeitos do resveratrol podem ser mediados por via da ativação de sirtuína sendo que esse grupo de gene "controla a atividade de funções vitais para a manutenção da sobrevivência das células" $(21,36)$.

A ação dos flavonoides, presentes no suco de uva e no vinho tinto, está relacionada à capacidade de dilatação de vasos sanguíneos e, como consequência a ação benéfica sobre o coração. Ademais, considerando a ingestão de vinho, o uso moderado de álcool mostra-se associado à diminuição da piora na função cognitiva em mulheres ao longo dos anos. O resveratrol, também, é considerado grande coadjuvante na prevenção da Doença de Alzhei- mer, onde atua evitando o envelhecimento das células cerebrais e o surgimento de depressão $(19,37)$.

A perda de cardiomiócitos por meio de apoptose tem sido proposta como causa de remodelamento ventricular e insuficiência cardíaca. Um estudo realizado em células embrionárias de coração de rato $\mathrm{H} 9 \mathrm{c} 2$ indicou que o resveratrol inibiu a apoptose induzida pela hipóxia através da via SIRT1-FoxO1 nas células estudadas, o que indica potencial na prevenção de doenças cardiovasculares, especialmente em pacientes com doença arterial coronariana (38).

Para tratamento de diabetes tipo 2, não dependente de insulina, o consumo moderado melhora a sensibilidade das células periféricas à insulina, e pode até ajudar a diminuir as chances de mulheres se tornarem diabéticas. Os polifenois são potentes varredores de radicais livres, prevenindo a degeneração macular, principal causa de cegueira entre as pessoas com mais de 65 anos. Indivíduos com o hábito de beber vinho têm $20 \%$ menos de cegueira, por idade, o que comprova que o consumo moderado de vinho está associado com diminuição da probabilidade de desenvolver degeneração macular relacionada com o envelhecimento $(19,39)$.

Alguns estudos epidemiológicos sugeriram que o risco de morte por problemas cardíacos e o surgimento de câncer é menor entre pessoas que ingerem baixas quantidades de álcool, sobretudo vinho tinto, do que entre abstêmios (22) e o resveratrol apresenta, entre seus efeitos positivos que podem ser destacados, o aumento da expectativa de vida e a redução do risco de desenvolvimento de diversos tipos de cânceres em diferentes mecanismos, a diminuição da proliferação de células tumorais, a regulação do ciclo celular e a modulação de enzimas antioxidantes e anti-inflamatórias (40).

Baseado na atividade antioxidante do resveratrol, um estudo foi desenvolvido para a investigação de seu efeito na replicação do vírus Influenza in vivo e in vitro. Foi verificado que o resveratrol inibiu fortemente a replicação do vírus da gripe nas células MDCK (MadinDarby Canine Kidney) e que esta atividade não estava diretamente relacionada à propriedade antioxidante mediada pela glutationa, mas sim, no bloqueio da translocação citoplasmática nuclear de ribonucleoproteínas virais reduzindo a expressão de proteínas virais tardias aparentemente relacionadas com a inibição da atividade da proteína quinase $\mathrm{C}$ e das suas vias dependentes. Houve melhora significativa na sobrevivência e diminuição dos títulos virais pulmonares nos animais infectados com o vírus da gripe (41). 
Em relação a outros microrganismos ensaiados, há registro de patente que foi publicado em 2006 onde foi evidenciado que o resveratrol, nas concentrações de 25 $\mathrm{mg} / \mathrm{mL}$ e $75 \mathrm{mg} / \mathrm{mL}$ foi capaz de inibir o crescimento Neisseria gonorrhoeae em 50\% e 100\% respectivamente. Em relação à Neisseria meningiditis, nas concentrações de $100 \mathrm{mg} / \mathrm{mL}$ e $125 \mathrm{mg} / \mathrm{mL}$ foi capaz de inibir em $50 \%$ e $100 \%$, respectivamente (42).

Para avaliar possíveis efeitos anti-inflamatórios e antiaterogênicos do resveratrol, um estudo utilizou modelo animal experimental com coelhos alimentados com dieta hipercolesterolêmica ( $1 \%$ de colesterol) concluindo que o resveratrol apresentou importantes efeitos antiaterogênicos e anti-inflamatórios (43). Outro estudo, sobre a atuação no metabolismo do colesterol e aterosclerose, evidenciou que as vias para fundamentar a cardioproteção mediada pelo resveratrol incluem a redução do estresse oxidativo e a ativação da sintetase endotelial do óxido nítrico (44).

Os efeitos hipoglicemiantes do resveratrol indicam ser o resultado de ação aumentada do transportador de glicose. Estudos sobre diabetes utilizando a indução por estreptozotocina em ratos demonstraram que a expressão do transportador de glicose dependente de insulina, GLUT4 aumenta após a ingestão de resveratrol. Além disso, o resveratrol aumenta os níveis de adiponectina o que pode ser o mecanismo em potencial pelo qual melhora a sensibilidade à insulina e induz a secreção do hormônio incretina intestinal, semelhante ao glucagon Peptídeo-1 (45).

Outra propriedade que merece ser mencionada e atribuída ao resveratrol é o auxílio no tratamento contra a obesidade, que vem sendo considerada como agravo à saúde de grande impacto à saúde pública em decorrência de sua prevalência, em nível mundial. Um estudo abordou o desenvolvimento de arroz transgênico enriquecido com resveratrol $(1,4 \mathrm{mg} / \mathrm{g}$ do composto em seu grão, DJ-526) para a alimentação de ratos que mostrou efeito contra a obesidade com excelente redução dos pesos corporais e os volumes de gordura abdominal, em comparação com o controle de $20,0 \%$ e $31,3 \%$, respectivamente. Além disso, houve melhora significativa do perfil lipídico no sangue e nos níveis de glicose podendo ser uma alternativa para a obesidade (46).

Portanto, embora muitos mecanismos de ação do resveratrol não tenham sido completamente definidos ou elucidados, foi verificada sua importância em relação às propriedades antioxidante, anti-inflamatória, antifibrótica, anticancerígena cardioprotetora, além de reduzir a agregação plaquetária, induzir vaso relaxamento, limitar a ativação endotelial e modular o metabolismo lipídico e lipoproteico. Os mecanismos adenosinérgicos podem desempenhar papel na sua atividade ateroprotetora $(32,44)$.

Considerando os estudos mencionados anteriormente, o resveratrol é um componente de vinho tinto de muita importância, produto que continua como sendo a sua principal fonte, pois a presença do álcool aumenta a sua solubilidade (40).

\section{CONCLUSÃO}

O vinho, desde a Antiguidade, tem sido considerado uma bebida que promove efeitos benéficos ao organismo. Composto de aproximadamente 400 substâncias, o vinho é capaz de evitar a oxidação das células, reduzir a formação de placas de gordura nas veias, aumentar o bom colesterol, dilatar os vasos e melhorar a circulação entre outras ações farmacológicas relacionadas à manutenção da qualidade de vida. Sendo cada vez mais pesquisado, seus benefícios estão relacionados, principalmente, com a presença de resveratrol em sua composição que se encontra em maior quantidade no vinho tinto (quando as cascas estão presentes na fermentação). Existem diversos estudos que comprovam os seus benefícios para o organismo humano, embora, sua farmacocinética ainda não esteja totalmente definida.

Pode-se afirmar que o consumo moderado e regular de vinho pode ajudar na prevenção de diversas doenças, entretanto, as características pessoais deverão nortear a administração, considerando a presença de álcool em sua composição, além do que, cada indivíduo precisa ser entendido em sua totalidade e complexidade quanto ao seu estado de saúde para a segurança no seu uso. 


\section{REFERÊNCIAS}

1. Sautter CK, Denardin S, Alves AO, Mallmann CA, Penna NG, Hecktheuer LH. Determinação de resveratrol em sucos de uva no Brasil. Ciênc Tecnol Aliment. 2005; 25(3):437-442. DOI: 10.1590/S010120612005000300008 .

2. Camargo UA, Hoffmann A, Tonietto J. Progressos na viticultura brasileira.Rev Bras Fruticultura. 2011; 33(1): 144-149. DOI: 10.1590/S0100-29452011000500017.

3. Domeneghini DCSJ, Lemes SAF. Efeitos dos componentes do vinho na função cardiovascular. Rev Soc Bras Alim Nutri. 2011; (36):163-176.

4. Vaccari NFS, Soccol MCH, Ide GM. Compostos fenólicos em vinhos e seus efeitos antioxidantes na prevenção de doenças. Rev Cien Agrovet. 2008; (8):71-83.

5. Pandey KB, Rizv SI. Resveratrol may protect plasma proteins from oxidation under conditions of oxidative stress in vitro. Braz Chem Soc. 2010; 21(5):909-913. DOI: $10.1590 / \mathrm{S} 0103-50532010000500020$

6. Novaes RD, Peluzio MCG, Maldonado IRSCM. Resveratrol provoca efeitos antiaterogênicos em um modelo animal de aterosclerose. Arq Bras Cardiol. 2012; 98(2): 136-142. DOI: 10.1590/S0066782X2012000600014

7. Subbaramaiah, K, Chung WJ, Michaluart P, Telang N, Tanabe T, Inoue H, Jang M, Pezzuto, JM, Dannenberg AJ. Resveratrol inhibits ciclooxygenase-2 transcription and activity in phorbol ester-treated human mammary epithelial cells. J Biol Chem. 1998; 273(34):2187521882. DOI:10.1074/jbc.273.34.21875.

8. Séfora-Souza M, Angelis-Pereira MC. Mecanismos moleculares de ação anti-inflamatória e antioxidante de polifenóis de uvas e vinho tinto na aterosclerose. Rev Bras Plan Med. 2013; 15(4): 617-626. DOI: 10.1590/ S1516-05722013000400020.

9. Sousa Neto JA, Cosenza RM. Efeitos do vinho no sistema cardiovascular. Rev Méd MG. 1994; 4(3):27-32.

10. Pinto D. Manual Didático do Vinho Iniciação à enologia.

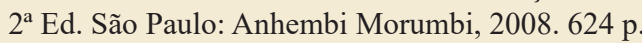

11. Grizzo A. A história do vinho e o vinho na história. Rev Adega. 2014. Disponível em: http://revistaadega. uol.com.br/artigo/historia-do-vinho-e-o-vinho-nahistoria_9693. html\#ixzz3HYJ4KPc3. Acesso em: 02 out 2014.

12. Bleche B. O mais completo guia sobre o Judaísmo. $1^{\mathrm{a}}$ ed. São Paulo: Sêfer, 2004. 496 p.

13. Almeida NA, Bragagnolo C, Chagas ALS. A Demanda por vinho no Brasil: elasticidades no consumo das famílias e determinantes da importação. Rev Econ Sociol Rural. 2015; 53(3):433-454. DOI: 10.1590/123456781806-9479005303004.

14. Afonso J. Os componentes do vinho - Parte 1. Rev Adega. 2006; 7. Disponível em: http://revistaadega.uol. com.br/artigo/os-componentes-do-vinho-parte-1_5934. html. Acesso em: 11 nov 2016.

15. Polifenóis: o que é? Disponível em: https://www. portaleducacao.com.br/nutricao/artigos/35007/ polifenois-o-que-e Acesso: em 10 nov 2016.

16. Acauan AP. Supermolécula pode prevenir doenças. PUCRS Informação. 2007; XXX(133):6-9.

17. Moraes V, Locatelli C. Vinho: uma revisão sobre a composição química e benefícios à saúde. Evidência. 2010; 10(12):57-68.

18. A química do vinho. Disponível em: http://www. academiadovinho.com.br/_ela_quimica.php. Acesso em: 14 nov 2016.

19. Oliveira CG. Vinho: riqueza de sabor e tradição. Rev Estar Bem. 2014; (2): 52-54.

20. Marinho A. A medicina do vinho fortalece o coração. Jornal O Globo. 11 de novembro de 2011. Disponível em: http://oglobo.globo.com/sociedade/saúde/a-medicinado-vinho-fortalece-coracao-3208872\#ixzz4PzKp7noC. Acesso em: 10 nov 2016.

21. Pivetta M. Estudos sugerem que compostos do vinho tinto aumentam a longevidade. Boletim da FAPESP. 2005; 112:44-47.

22. Mello JCP, Mentz LA, Petrovick PR, Schenkel EP, Simões CMO. Farmacognosia da planta ao medicamento.

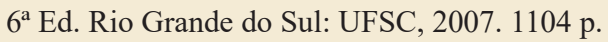

23. Soares SE. Ácidos fenólicos como antioxidantes. Rev Nutr. 2002; 15(1):71-78. DOI: 10.1590/S141552732002000100008.

24. Faller ALK, Fialho E. Disponibilidade de polifenóis em frutas e hortaliças consumidas no Brasil. Rev Saú Públ. 2009; 43(2):211-218.

25. Melo PS, Bergamaschi KB, Tiveron AP, Massarioli AP, Oldoni TLC, Zanus MC, Pereira GP, Alencar SM. Composição fenólica e atividade antioxidante de resíduos agroindustriais. Rev Ciên Rural. 2011; 41(6):1088-1093.

26. Angelo PM, Neuza J. Compostos fenólicos em alimentos: uma breve revisão. Rev Inst Adolfo Lutz. 2007; 66(1):19.

27. Machado WM, Pereira AD, Marcon MV. Efeito do processamento e armazenamento em compostos fenólicos presentes em frutas e hortaliças. Ci Agr Eng. 2013; 19(1):17-30. DOI: 10.5212/Publ.Exatas.v.19i1.0002.

28. Sautter CK, Denardin S, Alves AO, Mallmann CA, Penna NG, Hecktheuer LH. Determinação de resveratrol em sucos de uva no Brasil. Ciênc Tecnol Aliment. 2005; 25(3):437-442. DOI: 10.1590/S010120612005000300008.

29. Vélez-Marín M, Uribe-Velásquez LF, Souza MIL. Papel del resveratrol de uva como antioxidante. Luna Azul. 2012; (34):240-256. 
30. David JMP, David JP, Mota MD, Santos MLS, Santos VLCS. Resveratrol: ações e benefícios à saúde humana. Rev Rede Ensi FTC. 2007; 10:1-10.

31. Albertoni G, Schor N. Resveratrol plays important role in protective mechanisms in renal disease. $\mathrm{J}$ Bras Nefrol. 2015; 37(1): 106-114. DOI: 10.5935/01012800.20150015 .

32. Frémont L. Biological effects of resveratrol. Life Sci. 2000; 66(8):663-673. DOI: 10.1016/S00243205(99)00410-5.

33. Belguendouz FL, Gozzelino MT. Interaction of transreveratrol with plasma lipoproteins. Biochem Pharmacol. 1998; 15(55):811-816. DOI: 10.1016/S00062952(97)00544-3.

34. Bradamante S, Barenghi L, Villa A. Cardiovascular protective effects of resveratrol. Cardiovasc Drug Rev. 2004; 22(3):169-188. DOI: 10.1111/j.1527-3466.2004. tb00139.x.

35. Soares Filho PR, Castro I, Stahlschmidt A. Efeito do vinho tinto associado ao exercício físico no sistema cardiovascular de ratos espontaneamente hipertensos. Arq Bras Cardiol. 2011; 96(4):277-283. DOI: 10.1590/ S0066-782X2011005000020.

36. Voloshyna I, Hussaini SM, Reiss AB, Resveratrol in cholesterol metabolism and atherosclerosis. J Med Food. 2012; 15(9):763-773. DOI: 10.1089/jmf.2012.0025.

37. Luz PL. Álcool e coração. Arq Méd ABC. 2006; (2):810.

38. Chen CJ, Yu W, Fu YC, Wang X, Li JL, Wang W. Resveratrol protects cardiomyocytes from hypoxiainduced apoptosis through the SIRT1-FoxO1 pathway. Biochem Biophys Res Commun. 2009 16;378(3):389393. DOI: 10.1016/j.bbrc.2008.11.110.
39. Obisesan TO, Hirsch R, Kosoko O, Carlson L, Parrott M. Moderate wine consumption is associated with decreased odds of developing age-related macular degeneration in NHANES-1. JAGS. 1998; 46(1): 1-7. DOI: 10.1111/ j.1532-5415.1998.tb01005.x.

40. Resveratrol no combate ao câncer. 2012. Fundação do Câncer. Disponível em: https://www.cancer.org.br/ resveratrol-no-combate-ao-cancer/. Acesso em: 20 nov 2016.

41. Palamara AT, Nencioni L, Aquilano K, de Chiara G, Hernandez L, Cozzolino F, Ciriolo MR, Garaci E. Inhibition of Influenza a vírus replication by resveratrol. J Infect Dis. 2005; 191(10)1719-1729. DOI: $10.1086 / 429694$

42. Docherly J, inventor; Northeastem Ohio Universities College of Medicine, depositante. Method of inhibiting formation of Neisseria gonorrhea and Neisseria meningiditis. US patente 7037945 B2. 2006 mai 02.

43. Matos RS, Baroncini LAV, Précoma B, Winter G, Caron PHL, Kaiber F, Précoma DB. Resveratrol provoca efeitos antiaterogênicos em um modelo animal de aterosclerose. Arq Bras Cardiol. 2012; 98(2):136-142. DOI: 10.1590/ S0066-782X2012005000006.

44. Voloshyna I, Hussaini SM, Reiss AB. Resveratrol in cholesterol metabolism and atherosclerosis. J Med Food. 2012; 15(9):763-773. DOI: 10.1089/jmf.2012.0025.

45. Villianou NG, Evangelopoulos A, Kazazis C. Resveratrol and diabetes. Rev Diabet Stud. 2013; 10(4):236-242. DOI: 10.1900/RDS.2013.10.236.

46. Baek SH, Chung HJ, Lee HK, D'Souza R, Jeon Y, Kim HJ, Kweon SJ, Hong ST. Treatment of obesity with the resveratrol-enriched rice DJ-526. Sci Rep. 2014; 4:3879.16p. DOI:10.1038/srep03879. 